\title{
Smartphone Addiction and Associated Factors among Postgraduate Students in an Arabic Sample: A Cross-Sectional Study.
}

\section{Asem Alageel ( $\nabla$ asemalageel@yahoo.com )}

Imam Muhammad bin Saud Islamic University College of Medicine

\section{Rayyan Abdullah Alyahya}

Imam Muhammad bin Saud Islamic University College of Medicine

\section{Yasser Bahatheq}

Imam Muhammad bin Saud Islamic University College of Medicine

Norah Alzunaydi

Alamal Complex for Mental Health

\section{Raed Alghamdi}

Imam Muhammad bin Saud Islamic University College of Medicine

Nader Alrahili

Imam Muhammad bin Saud Islamic University College of Medicine

\section{Roger Mclntyre}

University of Toronto

Michelle lacobucci

University Health Network, Toronto

\section{Primary research}

Keywords: smartphones, society, highly impactful technologies, individual lives, mental health issues

Posted Date: December 1st, 2020

DOI: https://doi.org/10.21203/rs.3.rs-113781/v1

License: (c) (1) This work is licensed under a Creative Commons Attribution 4.0 International License. Read Full License 


\section{Smartphone addiction and associated factors among postgraduate students in an}

\section{Arabic sample: A cross-sectional study.}

3 Asem A. Alageel ${ }^{1}$ Rayyan A. Alyahya ${ }^{2}$ Y. Bahatheq ${ }^{3}$ Norah A. Alzunaydi ${ }^{4}$ Raed A. Alghamdi ${ }^{5}$

$4 \quad$ N. Alrahili $^{6}$, Roger S. Mclntyre ${ }^{7}$, Michelle lacobucci $^{8}$

\section{Introduction:}

6 Smartphones are handheld mobile devices with an internet connection and the ability to run 7 additional software (Email, social media, webbrowser..etc). The first smartphone was 8 produced in 1992, but the term "smartphone" was designated in 1995 ever since the functions 9 of a smartphone evolved to include more than communications. It now includes, but is not limited to, entertainment, social media, health monitoring, productivity, and utility functions such as day planners, and text and photo editing all in one handheld device. With this wide array of functionalities built into smartphones, researchers can now observe the increasing number of smartphone users. In 2017 Google announced that they had reached 2 billion active users, and in 2019 that the number had reached 2.5 billion (Google, 2019). Additionally, in 2019 Apple announced 900 million active users (Maestri, 2019). In 2019, Google and Apple collectively announced that there were 3.4 billion people using smartphones. These numbers do not consider the smartphone users who do not use Apple or Google products.

According to the American psychiatric association, addiction is "A complex condition, a brain disease that is manifested by compulsive substance use despite harmful consequences." Regardless of whether the addiction is substance or behavior related, there are five elements of addiction (Sussman et al., 2011). The first element is feeling different, which includes feeling relatively uncomfortable, lonely, restless, or incomplete (Jacobs et al., 1986). The second element of addiction is the preoccupation with the behavior, excessive thoughts about and desire to perform a behavior, excessive time spent to plan and engage in the behavior, and possibly recover from its effects, and less time spent on other activities (Campbell et al., 2003) despite potentially diminishing appetitive effects (Robinson et al., 2001) (Robinson et al., 
1 2008). Temporary Satiation is the third element of addiction, after acute engagement in an

2 addictive behavior, some period of time may occur in which urges are not operative, addiction

3 craving is "shut down", only to return soon (Foddy et al., 2010; Orford et al., 2001; Marks et

4 al., 1990). The fourth element is Loss of Control, wherein many people who claim to be

5 struggling with addiction experience feeling compelled to the addiction, a loss of control, and

6 in some cases, neglecting essential self-care, which suggests a loss of will (Nordenfelt et al.,

7 2010). The final element is negative consequences which means continuing to engage in the

8 addictive behavior after suffering numerous negative consequences. This last component of

9 addiction has often been a criterion of dependence on the addictive behavior (Goodman et 10 al., 1990)

12 "Smartphone addiction" could be considered as one form of technological addictions.

13 Generally, similar to internet addiction, smartphone addiction consists of four main components: compulsive behaviors, tolerance, withdrawal, and functional impairment (Block et al., 2008). In a study completed among 2367 university students in Riyadh, results indicated that $27.2 \%$ of participants stated that they spent more than 8 hours per day using their smartphones (Alosaimi et al., 2016). In another study done on 688 Lebanese university students, $49 \%$ reported excessive smartphone use ( $\geq 5$ hours/weekday) (Boumosleh et al., 2017)

21 Major Depressive Disorder (MDD) is a mental illness portrayed by hindering changes to the way a person thinks, acts, and feels. It causes feelings of sadness and bitterness and a loss of enthusiasm when partaking in activities the individual once enjoyed. MDD can present with a wide variety of symptoms, including lack of appetite, fatigue, trouble sleeping (e.g., Insomnia), feelings of guilt, and thoughts of suicide. Contingent upon the severity of MDD, it can be associated with a degree of cognitive dysfunction affecting the capacity to perform 
1 everyday home and work activities by prompting an assortment of physical and emotional

2 issues (American Psychiatric Association, 2013) (Mclntyre et al., 2013) (Chen et al., 2013).

3 MDD seems to have a close relationship with addiction and substance abuse. Two

4 epidemiological studies in 1990 and 1994 have showcased evidence that mood disorders

5 increase the risk of Substance Use Disorders (SUD) (Regier et al., 1990) (Kessler et al., 1994).

6 One literature review examined the relationship between Alcohol Use Disorders (AUD) and

7 MDD and found a correlation between the two, where AUD would double the risk of developing

8 MDD and vice versa (Boden et al., 2011). Mood disorders and SUD comorbidity lowers the

9 prognosis and treatment outcome for each problem (Quello et al., 2005). However, there is

10 evidence to suggest that the successful treatment of a comorbid mood disorder would

11 decrease craving and substance abuse (Cornelius et al., 1997). Furthermore, the correlations

12 are not exclusive to substance addiction and several studies have concluded that behavioral

13 addictions (such as internet and smartphone addiction) can be associated with MDD (Kumar

14 et al., 2018) (Alhassan et al., 2018)

15 Insomnia is defined as a subjective perception of difficulty falling or staying asleep; it can have

16 acute episodes of one night or last chronically for up to several weeks or even months, it is

17 associated with decreased mental and physical Health-Related Quality of Life (HRQoL) scores

18 (Scalo et al., 2014), and psychiatric illness (Haynes et al., 2011). Furthermore, though

19 indirectly, it is associated with smartphone overuse (Demirci et al., 2015).

Attention-deficit hyperactivity disorder (ADHD) is a neurodevelopmental disorder with onset in childhood that may last into adulthood characterized by hyperactivity, impulsiveness, or inattentiveness, and often all three symptoms (DSM-IV-TR (APA, 2000) that interfere or affect the quality of social, academic or occupational performance or development (Batstra, et al., 2012). A study in different countries in America, Europe, and the Middle East, showed average adult ADHD prevalence of $3.4 \%$ with a higher percentage of high economic countries $(4.2 \%)$ compared to poor economic countries (1.9\%) (Fayyad et al., 2007). Adults with ADHD have a 
1 significantly high chance of suffering from depressive, antisocial personality, anxiety, and

2 substance use disorders (Faraone et al., 2000).

3 Past studies have been done on the prevalence of smartphone addiction and its relationship

4 to mental and physical issues, be that as it may, these investigations showcased a portion of

5 the components identified with smartphone addiction. In contrast, numerous elements, such

6 as ADHD or nicotine addiction, were left uninvestigated. The objective of this study is to

7 discover the level of relationship between Smartphone addiction and different elements

8 including, but not limited to, MDD, Nicotine Dependence, Quality of life, and Sleep to locate

9 standard variables among postgraduates that will ideally prompt awareness and knowledge

10 about smartphone addiction on society while surveying the level of its mental impacts.

11 The goal of this examination is to distinguish the prevalence of smartphone addiction among 12 postgraduate students. Because of the expanded apparent pressures that these individuals 13 experience (Pfeifer et al., 2008), we believe that Postgraduate students are an especially 14 vulnerable populace to smartphone addiction. Postgraduate students will, in general, use smartphones to communicate, access data they need in school as well as entertainment. As far as we know, no present investigations are recognizing the prevalence of smartphone addiction among arabian middle eastern postgraduate students. In this article, we will be investigating the prevalence of smartphone addiction among postgraduate students as well as assessing its relationship to social demographics, depression, ADHD, and nicotine dependence.

\section{Methods:}

A cross-sectional online survey filled by 558 Arabic participants, was sent via email and social media accounts for postgraduate education ( Twitter, Facebook, and WhatsApp) to postsecondary students. Participants were considered in the study if they were Postgraduates and smartphone users. Postgraduate students from 187 different universities participated in the study. Participants were studying in different countries around the world, including Saudi 
1 Arabia, Jordan, Egypt, Kuwait, Algeria, Bahrain, Iraq, Lebanon, Afghanistan, Ethiopia, Fiji,

2 Cyprus, Australia, England, United States, and Canada. We excluded fifty-two students from

3 the study due to incomplete questionnaires leaving us with a total of 506 participants. This

4 study was approved by the Institutional Review Board (IRB) of Imam Mohammad ibn Saud

5 Islamic University in Riyadh, Saudi Arabia.

6 The online survey consisted of 43 questions and took approximately 5 to 10 minutes to 7 complete; we divided it into six parts. The first part was concerned with socio-demographic 8 information (such as age and gender). The second and third parts included the Arabic9 validated versions of the Smartphone Addiction Scale (SAS) and the Patient Health 10 Questionnaire for Depression (PHQ9). The fourth part used Athens Insomnia Scale (AIS) to 11 assess the quality of sleep, and the fifth section concerned nicotine dependence and 12 implemented the Fagerstrom Test for Cigarette Dependence Questionnaire (FTCd) for assessment. Finally, the sixth section was the Adult ADHD Self-Report Scale (ASRS-v1.1)

14 Smartphone addiction was measured using the arabic version of Smartphone Addiction Scale (SAS). SAS is a self-diagnosis scale that was modified from K-scale which is a scale to assess Internet addiction for juveniles. SAS consists of 33 items with 6 subscales, which are daily life disturbance, positive anticipation, withdrawal, cyberspace-oriented relationship, overuse, and tolerance (Kwon et al., 2013). Items are scored on a six-point likert scale as follows: strongly disagree (1), disagree (2), weakly disagree (3), weakly agree (4), agree (5), strongly agree (6). The sum of the six subscales refers to SAS score with a range of 33 to 198 . Higher score means higher addictive behaviour with smartphones (Kwon et al., 2013). Data factorability for the arabic version of SAS was confirmed using Kaiser-Meyer-Olkin (KMO) test of sampling adequacy with a resulting value of 0.94 and supported with Bartlett's test of sphericity to verify the suitability of data for factor analysis which showed a significant value of $p<0.01$ (Sfendla et al., 2018). The internal consistency for Arabic SAS was calculated using Cronbach's alpha with a value of $a=0.94$ (Sfendla et al., 2018). In this study, we grouped participants who 
1 scored 116 or more in SAS in the high smartphone usage group and participants who scored

2 less were put in a low smartphone usage.

3 The second part of the questionnaire was the Patient Health Questionnaire for depression

4 (PHQ9), a self-report questionnaire designed to assess the level of depression over the last

5 two weeks, where higher scores indicated a higher chance of depression (Kroenke et al.,

6 2001). We used a validated and translated version to assess our Arabic population; it had

7 internal consistency reliability of 0.857 calculated using Cronbach's alpha (Alhadi et al., 2017).

8 We used the cut-off point of 10 for clinically significant depression; we then further classified

9 the depressed participants to clinically significant, moderately severe, and severe. We have

10 considered those who scored between 10-14 to have clinically significant depression, scores

11 that range between $15-19$ are moderately severe depression, and severe depression for

12 participants who scored more than 20. Participants who scored $15+$ warranted active

13 treatment (Kroenke et al., 2001).

14 Athens Insomnia Scale (AIS) was used to measure sleep quality, the English version had an optimum specificity of $85 \%$ and sensitivity of $93 \%$ (Soldatos et al., 2003), it assesses sleep quality over the last month, using a 4 point system of 0 to 3 , where zero means no insomnia symptoms and three means more acute sleep difficulties. In our study, we considered any participant with a score of 6 or more to have insomnia. We used an Arabic translated version by Toronto Sleep Clinics, an English-speaking healthcare professional whose mother tongue is Arabic translated the scale from English to Arabic, and using the same approach as the first translation, another translator did back-translation to English, a few English-speaking translators reviewed any problematic contextual discrepancies. However, it is yet to be tested 23 for validity.

24 The fifth part included Fagerstrom Test for Cigarette Dependence Questionnaire (FTCd) a 625 item questionnaire used to measure the nicotine dependence associated with cigarette 26 smoking, it uses a 10 point system, wherein we considered those who score less than four to 27 be minimally dependent, 4-6 were moderately dependent, 6-10 were highly dependent. FTCd 
1 was found to be moderately reliable on an Arabic sample and was valued 0.68 on the

2 Cronbach alpha coefficient (Kassim et al., 2012).

3 We used the validated arabic version Adult ADHD Self-Report Scale (ASRS-v1.1), a 6-item

4 screening tool for attention-deficit/hyperactivity disorder (ADHD) to assess Adult ADHD, it was

5 proven to be a reliable tool, with a sensitivity of (68.7\%), and specificity of $(99.5 \%)$, two-thirds

6 of clinical cases of ADHD scored 4-6 (Kessler et al., 2005)

\section{Results:}

8 The total number of participants in this study was 506, $158(31.23 \%)$ males, and $348(68.77 \%)$

9 females. $9.41 \%$ of participants were between 21 to 24 years old , $35.88 \%$ were between 25 to 1029 years of age $(P=0.007), 44.51 \%$ were from 30 to 39 years old, and $10.20 \%$ of the 11 participants were 40 years old and above. $46.18 \%$ of our respondents were single, $50.68 \%$

12 were married, and $3.13 \%$ were divorced. The majority of participants did not have any children 13 at $56.19 \%$. The participants were taking different majors, the majority of participants at $49.32 \%$ 14 were partaking courses in Humanities/Social sciences, $12.72 \%$ were studying 15 Biological/Physical Sciences, $12.92 \%$ were in Engineering, and $25.05 \%$ were from other unspecified majors. $67.72 \%$ of the participants were studying for a Master's degree; on the other hand, $32.28 \%$ were preparing their Ph.D. First-year students were $26.39 \%$, students in their second year were $32.08 \%$, third-year students were $20.40 \%$, while $10.30 \%$ of the students were in their fourth year and the same number of students were in their fifth year of studies. $33.86 \%$ of our participants are studying abroad, while $66.14 \%$ of students were studying in their country of origin. (Table 1) [Insert Table 1 Illustration Here]

According to the Smartphone Addiction Scale, $51.0 \%$ of the participants appear to be high smartphone users, while $49.0 \%$ are low smartphone users. (Table 2 )

24 Table 2: Prevalence of Depression and Anxiety disorders

\begin{tabular}{|l|l|l|}
\hline & Number & $\%$ \\
\hline Depression & 598 & 59.5 \\
\hline Moderate to Severe Depression & 133 & 13.2 \\
\hline
\end{tabular}




\begin{tabular}{|l|l|l|}
\hline Severe Depression & 143 & 14.2 \\
\hline Clinically significant Anxiety Disorder & 552 & 54.9 \\
\hline Severe Anxiety Disorder & 237 & 23.6 \\
\hline
\end{tabular}

1

2 Statistical analysis showed no significant relationship between smartphone use and most

3

4 sociodemographic characteristics which include: gender, marital status, number of children, studies majors, educational level, academic year, being outside the country, participants monthly income, family monthly income, GPA, and the number of published papers. However, it showed a statistically significant relationship between smartphone use and the population's age $(p=0.026) .($ Table 3$)$

In this research, $P$ values of $<0.05$ were considered statistically significant. Regarding highsmartphone use and age; $35.4 \%$ (17) of participants between the ages of 21-24 years of age, $57.3 \%(105)$ of people between the ages of $25-29,51.5 \%(117)$ of people of the age $30-39$, and $42.3 \%(22)$ of those above 40 years of age scored high on the SAS scale. (Table 3) [Insert Table 3 Illustration Here]

The PHQ-9 questionnaire for depression showed a significant association between high smartphone use and MDD ( $r=0.408)(p=0.001)$ (Table 4); $65.9 \%$ of participants with high smartphone use had no depression, while $10.3 \%$ had severe depression, $16.1 \%$ had moderately severe depression, and $7.7 \%$ of the participants had moderate depression. $81.7 \%$ of the non-smartphone addiction group showed no depression symptoms, while $6.0 \%$ showed severe depression, $4.4 \%$ showed moderately severe depression, and $8.0 \%$ showed moderate depression. Multivariate analysis showed an elevated risk of simultaneously having severe depression and smartphone addiction $(\mathrm{OR}=3.779)(\mathrm{P}=0.001)($ Table 2) $($ Table 5). In conclusion, high smartphone use is associated with a higher prevalence of depression. [Insert Table 4 and 5 Illustration Here]

We used the Fagerstrom Test to assess nicotine dependence. The total result showed a moderate positive significant Pearson Correlation coefficient between smartphone addiction and smoking $(r=0.323)(p=0.018) .20 .8 \%$ of our population are active smokers, $8.4 \%$ of those 
1 with smartphone addiction were smokers, which means that $41.5 \%$ of smokers were addicted

2 to smartphones $(p=0.039)$. (Table 4$)$

3 We measured Sleep difficulty by using Athens Insomnia Scale (AIS); it showed a significant

4 correlation between the severity of insomnia and smartphone use $(r=0.306)(p=0.001)$ (Table

54 ); $65.7 \%$ of those with high smartphone use had insomnia, and $34.3 \%$ did not. On the other

6 hand, only $44.4 \%$ of the non-smartphone addiction group had insomnia while $55.6 \%$ free of it,

7 which showcases a higher prevalence of insomnia among high smartphone users.

8 Smartphone addicts have about two times the risk of developing insomnia $(O R=2.113)(P=$

$9 \quad 0.013)($ Table 5).

10 We applied the Adult ADHD Self-Report Scale (ASRS-v1.1) symptom checklist to consider

11 ADHD symptoms. $47.8 \%$ of high smartphone use participants had ADHD symptoms. On the

12 other hand, $19.7 \%$ of the non-smartphone addiction group showed ADHD symptoms,

13 indicating a significant relationship between smartphone addiction and Adult ADHD symptoms

$14(r=0.405)(p=0.001)$ (Table 4). Those who were addicted to smartphone use had a significant

15 risk of developing ADHD symptoms $(\mathrm{OR}=2.712)(\mathrm{P}<0.001)$ (Table 5).

\section{Discussion:}

17 Our study reveals that $51 \%$ of our population scored high on the SAS. In a similar study in Lebanon, they used the Smartphone Addiction Inventory and found that $49 \%$ of university students had smartphone addiction (Boumosleh et al., 2017), while another study in Saudi Arabia found that $61 \%$ of university students had high smartphone use (Alosaimi et al., 2016).

21 We found a significant relationship between age and smartphone addiction, A study in Turkey suggested that gender and young age were independent factors for smartphone use. Women and younger populations may, therefore, be at higher risk for smartphone addiction (Demirci et al., 2015) however, our results show no significant relationship between gender and smartphone addiction. Reaffirming previous literature, we have found a significant positive 
1 similar association (Alhassan et al. 2018; Yen et al. 2009; Gao Y et al. 2017). In a review of

223 studies, it was found that depression is a consistent variable associated with smartphone

3 use (Elhai et al. 2017). A study on Korean adolescents found an association between

4 unhealthful lifestyle habits and smartphone addiction, linking unhealthy diets, weight gain, and

5 sleep disturbances to smartphone addiction, which are also considered to be symptoms and

6 consequences of MDD (Kim et al. 2018). A study done to university students in Saudi Arabia,

7 showcased that $43 \%$ of problematic smartphone users were found to have reduced sleeping

8 hours (Alosaimi et al. 2016). Our current research indicates that there is a strong association

9 between the use of smartphones and insomnia, where most of our subjects $(65.7 \%)$ reported

10 insomnia and high usage of smartphones. Intensive smartphone use was shown to be

11 positively correlated with poor sleep quality, and daytime sleepiness, which was consistent

12 with our findings (Spagnoli et al., 2019). In another study conducted at King Abdul-Aziz

13 University, Jeddah, showed that mobile use was highly prevalent among participants (73.4\% used them $>5 \mathrm{~h} /$ day), where two-thirds of participants had poor sleep quality and latency to sleep (Ibrahim et al. 2018). A Belgian study revealed that bedtime smartphone use indicated later self-reported rise time, higher insomnia score and increased fatigue (Exelmans et al., 2016). A study on students between the ages of 18 and 39 indicated that insomnia is associated with phone use (Fossum et al. 2013). The National sleep foundation's 2011 sleep in America poll showed results indicating that use of numerous technological devices before bedtime would lead to difficulty falling asleep (Gradisar et al., 2013). Confirming our finding of a higher prevalence of ADHD symptoms among those with smartphone addiction (47.8\%) compared to low-use smartphone users (19.7\%); An epidemiological study done on 4512 south korean adolescents using SAS examined the relationship between Smartphone addiction and symptoms of depression, anxiety and ADHD found that those with smartphone addiction had a higher likelihood of having ADHD symptoms (Kim et al., 2019). Studies have found similarities between Smartphone Addiction and Internet Addiction (IA) (Ben-Yehuda et al. 2016). A study comparing smartphone addiction and IA, using 12 addiction risk factors, found that there are several similar risk factors, such as depression, anxiety, self-control, life 
1 satisfaction, and aggression; the effects of the five identified addiction psychological factors

2 were all significant $(P<0.01)$ for both IA and smartphone addiction (Jeong et al., 2019). Current

3 results have shown a relationship between behavioral addictions and adult ADHD. A previous

4 similar study looked at the relationship between Internet addiction (IA) and symptoms of ADHD

5 severity and emotional distress through an online survey established a significant relationship

6 between the severity of IA symptoms and the presence and severity of ADHD symptoms

7 (Evren et al., 2018). furthermore, Studies showed that individuals with ADHD are more likely

8 to develop other types of behavioral addictions, such as gambling disorders. (Brandt et al., 9 2017; Fatseas et al., 2016). Adult ADHD is strongly associated with substance use disorder 10 in a literature review of Adult ADHD in the Arab World (Hayek et al., 2019).

\section{Limitations:}

12 Due to the nature of cross-sectional studies representing a single point of time rather than a 13 longitudinal observation, it is therefore not guaranteed to be representative of the population. 14 This research cannot be used to analyze the behavior of the population over a period of time. 15 Cross-sectional studies do not specify the cause of the disease. There is also a chance of recall bias on the part of participants. Since our study has been circulated online, through emails and various social media channels, it excludes people who develop MDD, Insomnia, and ADHD who do not have access to social media, or who are not interested in taking part in our questionnaire due to social stigma. Therefore, future research should involve participants who are more open to the idea of mental health and mental illness. Besides, while PHQ-9 is the most commonly used questionnaire for the diagnosis of MDD in clinical practice, it contains somatic symptoms such as exhaustion and poor appetite that can be attributed to other diseases, thereby placing the study at risk of overestimating MDD prevalence.

\section{Conclusion:}

In Conclusion, due to the ease of access and the utter dependence of smartphones in our daily lives, their mental and physical impacts should be studied across different populations. 
1 The post-graduate student population is underrepresented throughout the medical literature,

2 and we hope to extend the knowledge regarding post-graduate students to include

3 smartphone addiction. Confirming several studies, we found a positive association between

4 Insomnia, Depression, Adult ADHD, and Smartphone overuse. Therefore, we encourage the

5 scientific community to study the impacts of smartphone addiction and the mental health of

6 post-graduate students.

7 Finally, we recommend that smartphone addiction be carefully monitored for post-graduate

8 students displaying Depression, Insomnia, or ADHD.

9 Declarations:

10 Ethical Approval:

11 This study was approved by the Institutional Review Board (IRB) of Imam Mohammad ibn

12 Saud Islamic University in Riyadh, Saudi Arabia

13 Conflict of Interest:

14 Dr. Mclntyre reports grants from Stanley Medical Research Institute, and from

$15 \mathrm{CIHR/GACD/Chinese} \mathrm{National} \mathrm{Natural} \mathrm{Research} \mathrm{Foundation.} \mathrm{and} \mathrm{other} \mathrm{relationships} \mathrm{that}$ 16 may include consultations/speaker fees, from Lundbeck, Janssen, Shire, Purdue, Pfizer,

17 Otsuka, Allergan, Takeda, Neurocrine, Sunovion, Minerva outside the submitted work.

18 All other authors declare that they have no conflicts of interest.

19 Funding:

20 This research was supported by the Deanship of Scientific Research, Al-Imam Mohammad

21 Ibn Saud Islamic University (IMSIU), Saudi Arabia,

22 Consent for publication:

23 Not Applicable

24 Availability of Data and Materials: 
1 The datasets analyzed during the current study available from the corresponding author on

2 reasonable request.

3 Contribution:

4 All of the authors participating in the research have contributed to the manuscript and

5 approved the last version of the manuscript

\section{Acknowledgements:}

7 We would like to express our sincere gratitude to the Deanship of Academic Research, Al-

8 Imam Mohammad Ibn Saud Islamic University (IMSIU), and SABIC Psychological Health

9 Research \& Applications Chair (SPHRAC).

\section{References:}

11 Alhadi, A. N., Alateeq, D. A., Al-Sharif, E., Bawazeer, H. M., Alanazi, H., Alshomrani, A. T., ... 12 Alowaybil, R. (2017). An arabic translation, reliability, and validation of Patient Health 13 Questionnaire in a Saudi sample. Annals of General Psychiatry, 16(1). 14 https://doi.org/10.1186/s12991-017-0155-1

15 Alhassan, A. A., Alqadhib, E. M., Taha, N. W., Alahmari, R. A., Salam, M., \& Almutairi, A. F. 16 (2018). The relationship between addiction to smartphone usage and depression among 17 adults: a cross sectional study. BMC Psychiatry, 18(1). https://doi.org/10.1186/s12888-018$18 \quad 1745-4$

19 Alosaimi, F., Alyahya, H., Alshahwan, H., Mahyijari, N. A., \& Shaik, S. (2016). Smartphone 20 addiction among university students in Riyadh, Saudi Arabia. Saudi Medical Journal, 37(6), 21 675-683. https://doi.org/10.15537/smj.2016.6.14430

22 American Psychiatric Association (2013). Diagnostic and Statistical Manual of Mental 23 Disorders. https://doi.org/10.1176/appi.books.9780890425596 
1 Batstra, L., \& Frances, A. (2012). DSM-5 Further Inflates Attention Deficit Hyperactivity

2 Disorder. The Journal of Nervous and Mental Disease, 200(6), 486-488.

3 https://doi.org/10.1097/nmd.0b013e318257c4b6

4 Ben-Yehuda, L., Greenberg, L., \& Weinstein, A. (2016). Internet Addiction by Using the

5 Smartphone-Relationships between Internet Addiction, Frequency of Smartphone Use and

6 the State of Mind of Male and Female Students. Journal of Reward Deficiency Syndrome and

7 Addiction Science, 2(1). https://doi.org/10.17756/jrdsas.2016-024

8 Block, J. J. (2008). Issues for DSM-V: Internet Addiction. American Journal of Psychiatry, 9 165(3), 306-307. https://doi.org/10.1176/appi.ajp.2007.07101556

10 Boden, J. M., \& Fergusson, D. M. (2011). Alcohol and depression. Addiction, 106(5), 90611 914. https://doi.org/10.1111/j.1360-0443.2010.03351.x

12 Boumosleh, J. M., \& Jaalouk, D. (2017). Depression, anxiety, and smartphone addiction in 13 university students- A cross sectional study. Plos One, 12(8). 14 https://doi.org/10.1371/journal.pone.0182239

15 Brandt, L., \& Fischer, G. (2017). Adult ADHD Is Associated With Gambling Severity and 16 Psychiatric Comorbidity Among Treatment-Seeking Problem Gamblers. Journal of Attention 17 Disorders, 23(12), 1383-1395. doi:10.1177/1087054717690232

18 Campbell, W. G. (2003). Addiction: A Disease of Volition Caused by a Cognitive Impairment. 19 The Canadian Journal of Psychiatry, 48(10), 669-674. 20 https://doi.org/10.1177/070674370304801005

21 Chen, L., Wang, L., Qiu, X. H., Yang, X. X., Qiao, Z. X., Yang, Y. J., \& Liang, Y. (2013). 22 Depression among Chinese University Students: Prevalence and Socio-Demographic 23 Correlates. PLoS ONE, 8(3). https://doi.org/10.1371/journal.pone.0058379

24 Choi, S.-W., Kim, D.-J., Choi, J.-S., Ahn, H., Choi, E.-J., Song, W.-Y., ... Youn, H. (2015).

25 Comparison of risk and protective factors associated with smartphone addiction and Internet 
1 addiction. Journal of Behavioral Addictions, 4(4), 308-314.

2 https://doi.org/10.1556/2006.4.2015.043

3 Choi, S.-W., Mok, J. Y., Kim, D.-J., Choi, J.-S., Lee, J.-W., Ahn, H.-J., .. Song, W.-Y. (2014).

4 Latent class analysis on internet and smartphone addiction in college students.

$5 \quad$ Neuropsychiatric Disease and Treatment, 817. https://doi.org/10.2147/ndt.s59293

6 Cornelius, J. R. (1997). Fluoxetine in Depressed Alcoholics. Archives of General Psychiatry,

7 54(8), 700. https://doi.org/10.1001/archpsyc.1997.01830200024004

8 Demirci, K., Akgönül, M., \& Akpinar, A. (2015). Relationship of smartphone use severity with

9 sleep quality, depression, and anxiety in university students. Journal of Behavioral Addictions,

10 4(2), 85-92. https://doi.org/10.1556/2006.4.2015.010

11 Elhai, J. D., Dvorak, R. D., Levine, J. C., \& Hall, B. J. (2017). Problematic smartphone use: A conceptual overview and systematic review of relations with anxiety and depression psychopathology. Journal of Affective Disorders, 207, 251-259. https://doi.org/10.1016/j.jad.2016.08.030

15 Evren, B., Evren, C., Dalbudak, E., Topcu, M., \& Kutlu, N. (2018). Relationship of internet 16 addiction severity with probable $A D H D$ and difficulties in emotion regulation among young 17 adults. Psychiatry Research, 269, 494-500. https://doi.org/10.1016/j.psychres.2018.08.112

18 Exelmans, L., \& Bulck, J. V. (2016). Bedtime mobile phone use and sleep in adults. Social 19 Science \& Medicine, 148, 93-101. doi:10.1016/j.socscimed.2015.11.037

20 Faraone, S. V., Biederman, J., Spencer, T., Wilens, T., Seidman, L. J., Mick, E., \& Doyle, A. 21 E. (2000). Attention-deficit/hyperactivity disorder in adults: an overview. Biological Psychiatry, 48(1), 9-20. https://doi.org/10.1016/s0006-3223(00)00889-1

23 Fatséas, M., Hurmic, H., Serre, F., Debrabant, R., Daulouède, J.-P., Denis, C., \& Auriacombe, M. (2016). Addiction severity pattern associated with adult and childhood Attention Deficit 
1 Hyperactivity Disorder (ADHD) in patients with addictions. Psychiatry Research, 246, 656-

$2 \quad$ 662. https://doi.org/10.1016/j.psychres.2016.10.071

3 Fatséas, M., Hurmic, H., Serre, F., Debrabant, R., Daulouède, J., Denis, C., \& Auriacombe, 4 M. (2016). Addiction severity pattern associated with adult and childhood Attention Deficit 5 Hyperactivity Disorder (ADHD) in patients with addictions. Psychiatry Research, 246, 6566 662. doi:10.1016/j.psychres.2016.10.071

7 Fayyad, J., Graaf, R. D., Kessler, R., Alonso, J., Angermeyer, M., Demyttenaere, K., ... Jin, 8 R. (2007). Cross-national prevalence and correlates of adult attention-deficit hyperactivity 9 disorder. British Journal of Psychiatry, 190(5), 402-409. 10 https://doi.org/10.1192/bjp.bp.106.034389

11 Foddy, B., \& Savulescu, J. (2010). Relating Addiction to Disease, Disability, Autonomy, and 12 the Good Life. Philosophy, Psychiatry, \& Psychology, 17(1), 35-42. 13 https://doi.org/10.1353/ppp.0.0284

14 Fossum, I. N., Nordnes, L. T., Storemark, S. S., Bjorvatn, B., \& Pallesen, S. (2013). The 15 Association Between Use of Electronic Media in Bed Before Going to Sleep and Insomnia 16 Symptoms, Daytime Sleepiness, Morningness, and Chronotype. Behavioral Sleep Medicine, 17 12(5), 343-357. https://doi.org/10.1080/15402002.2013.819468

18 Gao, T., Xiang, Y.-T., Zhang, H., Zhang, Z., \& Mei, S. (2017). Neuroticism and quality of life: 19 Multiple mediating effects of smartphone addiction and depression. Psychiatry Research, 258, 457-461. https://doi.org/10.1016/j.psychres.2017.08.074

21 Goodman, A. (1990). Addiction: definition and implications. Addiction, 85(11), 1403-1408. https://doi.org/10.1111/j.1360-0443.1990.tb01620.x

23 Google I/O Developer Conference, 2019

24 Gradisar, M., Wolfson, A. R., Harvey, A. G., Hale, L., Rosenberg, R., \& Czeisler, C. A. (2013).

25 The Sleep and Technology Use of Americans: Findings from the National Sleep Foundation's 
12011 Sleep in America Poll. Journal of Clinical Sleep Medicine, 09(12), 1291-1299.

2 https://doi.org/10.5664/jcsm.3272

3 Hayek, G. E., Saab, D., Farhat, C., Krayem, Z., \& Karam, E. (2019). Adult ADHD in the Arab

4 World: A review. Archives of Psychology, 3(7). https://doi.org/10.31296/aop.v3i7.115

5 Haynes, P. L., Parthasarathy, S., Kersh, B., \& Bootzin, R. R. (2011). Examination of insomnia

6 and insomnia treatment in psychiatric inpatients. International Journal of Mental Health

7 Nursing, 20(2), 130-136. https://doi.org/10.1111/j.1447-0349.2010.00711.x

8 Ibrahim, N. K., Baharoon, B. S., Banjar, W. F., Jar, A. A., Ashor, R. M., Aman, A. A., \& Al9 Ahmadi, J. R. (2018). Mobile Phone Addiction and Its Relationship to Sleep Quality and 10 Academic Achievement of Medical Students at King Abdulaziz University, Jeddah, Saudi 11 Arabia. Journal of research in health sciences, 18(3), e00420.

12 Jacobs, D. F. (1986). A general theory of addictions: A new theoretical model. Journal of 13 Gambling Behavior, 2(1), 15-31. https://doi.org/10.1007/bf01019931

14 Jeong, Y. J., Suh, B., \& Gweon, G. (2019). Is smartphone addiction different from Internet 15 addiction? comparison of addiction-risk factors among adolescents. Behaviour \& Information 16 Technology, 39(5), 578-593. https://doi.org/10.1080/0144929x.2019.1604805

17 Kassim, S., Salam, M., \& Croucher, R. (2012). Validity and Reliability of the Fagerstrom Test 18 for Cigarette Dependence in a Sample of Arabic Speaking UK-Resident Yemeni Khat 19 Chewers. Asian Pacific Journal of Cancer Prevention, 13(4), 1285-1288. 20 https://doi.org/10.7314/apjcp.2012.13.4.1285

21 Kessler, R. C. (1994). Lifetime and 12-Month Prevalence of DSM-III-R Psychiatric Disorders 22 in the United States. Archives of General Psychiatry, 51(1), 8. 23 https://doi.org/10.1001/archpsyc.1994.03950010008002

24 Kessler, R. C., Adler, L., Ames, M., Demler, O., Faraone, S., Hiripi, E., ... Walters, E. E. (2005).

25 The World Health Organization adult ADHD self-report scale (ASRS): a short screening scale 
1 for use in the general population. Psychological Medicine, 35(2), 245-256.

2 https://doi.org/10.1017/s0033291704002892

3 Kim, Y.-J., Jang, H., Lee, Y., Lee, D., \& Kim, D.-J. (2018). Effects of Internet and Smartphone

4 Addictions on Depression and Anxiety Based on Propensity Score Matching Analysis.

5 International Journal of Environmental Research and Public Health, 15(5), 859.

6 https://doi.org/10.3390/ijerph15050859

7 Kim, S., Park, J., Kim, H., Pan, Z., Lee, Y., \& Mcintyre, R. S. (2019). The relationship between

8 smartphone addiction and symptoms of depression, anxiety, and attention-deficit/hyperactivity

9 in South Korean adolescents. Annals of General Psychiatry, 18(1). doi:10.1186/s12991-019-

$10 \quad 0224-8$

11 Kroenke, K., Spitzer, R. L., \& Williams, J. B. (2001). The PHQ-9. Journal of General Internal 12 Medicine, 16(9), 606-613. doi:10.1046/j.1525-1497.2001.016009606.x

13 Kumar, S., Kumar, A., Badiyani, B., Singh, S. K., Gupta, A., \& Ismail, M. B. (2018).

14 Relationship Of Internet Addiction With Depression And Academic Performance In Indian

15 Dental Students. Medicine and Pharmacy Reports, 91(3), 300-306.

16 https://doi.org/10.15386/cjmed-796

17 Kwon, M., Kim, D.-J., Cho, H., \& Yang, S. (2013). The Smartphone Addiction Scale:

18 Development and Validation of a Short Version for Adolescents. PLoS ONE, 8(12).

19 https://doi.org/10.1371/journal.pone.0083558

20 Lee, Y. S., Han, D. H., Kim, S. M., \& Renshaw, P. F. (2013). Substance abuse precedes 21 internet addiction. Addictive Behaviors, 38(4), 2022-2025.

22 https://doi.org/10.1016/j.addbeh.2012.12.024

23 Maestri, L. (2019). Financial Times. other, Financial Times. https://www.ft.com.

24 Marks, I. (1990). Behavioural (non-chemical) addictions. Addiction, 85(11), 1389-1394.

25 https://doi.org/10.1111/j.1360-0443.1990.tb01618.x 
1 Mcintyre, R. S., Cha, D. S., Soczynska, J. K., Woldeyohannes, H. O., Gallaugher, L. A.,

2 Kudlow, P., ... Baskaran, A. (2013). Cognitive Deficits And Functional Outcomes In Major

3 Depressive Disorder: Determinants, Substrates, And Treatment Interventions. Depression

4 and Anxiety, 30(6), 515-527. https://doi.org/10.1002/da.22063

5 Mei, S., Gao, T., Li, J., Zhang, Y., Chai, J., Wang, L., ... Zhang, H. (2017). Internet addiction

6 in college students and its relationship with cigarette smoking and alcohol use in Northeast

7 China. Asia-Pacific Psychiatry, 9(4). https://doi.org/10.1111/appy.12281

8 Nordenfelt, L. (2010). On Concepts and Theories of Addiction. Philosophy, Psychiatry, \& 9 Psychology, 17(1), 27-30. https://doi.org/10.1353/ppp.0.0271

10 Orford, J. (2001). Addiction as excessive appetite. Addiction, 96(1), 15-31.

11 https://doi.org/10.1046/j.1360-0443.2001.961152.x

12 Pfeifer, T. A., Kranz, P. L., \& Scoggin, A. E. (2008). Perceived stress in occupational therapy students. Occupational Therapy International, 15(4), 221-231. https://doi.org/10.1002/oti.256

14 Quello, S., Brady, K., \& Sonne, S. (2005). Mood Disorders and Substance Use Disorder: A 15 Complex Comorbidity. Science \& Practice Perspectives, 3(1), 13-21. 16 https://doi.org/10.1151/spp053113

17 Regier, D. A. (1990). Comorbidity of Mental Disorders With Alcohol and Other Drug Abuse. 18 Jama, 264(19), 2511. https://doi.org/10.1001/jama.1990.03450190043026

19 Robinson, T. E., \& Berridge, K. C. (2001). Incentive-sensitization and addiction. Addiction, 96(1), 103-114. https://doi.org/10.1046/j.1360-0443.2001.9611038.x

21 Robinson, T. E., \& Berridge, K. C. (2008). The incentive sensitization theory of addiction: some

22 current issues. Philosophical Transactions of the Royal Society B: Biological Sciences, 23 363(1507), 3137-3146. https://doi.org/10.1098/rstb.2008.0093 
1 Scalo, J., Desai, P., \& Rascati, K. (2014). Insomnia, hypnotic use, and health-related quality

2 of life in a nationally representative sample. Quality of Life Research, 24(5), 1223-1233.

3 https://doi.org/10.1007/s11136-014-0842-1

4 Sfendla, A., Laita, M., Nejjar, B., Souirti, Z., Touhami, A. A. O., \& Senhaji, M. (2018). Reliability

5 of the Arabic Smartphone Addiction Scale and Smartphone Addiction Scale-Short Version in

6 Two Different Moroccan Samples. Cyberpsychology, Behavior, and Social Networking, 21(5),

7 325-332. https://doi.org/10.1089/cyber.2017.0411

8 Soldatos, C. R., Dikeos, D. G., \& Paparrigopoulos, T. J. (2003). The diagnostic validity of the

9 Athens Insomnia Scale. Journal of Psychosomatic Research, 55(3), 263-267.

10 https://doi.org/10.1016/s0022-3999(02)00604-9

11 Spagnoli, Balducci, Fabbri, Molinaro, \& Barbato. (2019). Workaholism, Intensive Smartphone

12 Use, and the Sleep-Wake Cycle: A Multiple Mediation Analysis. International Journal of

13 Environmental Research and Public Health, 16(19), 3517.

14 https://doi.org/10.3390/ijerph16193517

15 Sussman, S., \& Sussman, A. N. (2011). Considering the Definition of Addiction. International 16 Journal of Environmental Research and Public Health, 8(10), 4025-4038.

17 https://doi.org/10.3390/ijerph8104025

18 Yen, C.-F., Tang, T.-C., Yen, J.-Y., Lin, H.-C., Huang, C.-F., Liu, S.-C., \& Ko, C.-H. (2009).

19 Symptoms of problematic cellular phone use, functional impairment and its association with 20 depression among adolescents in Southern Taiwan. Journal of Adolescence, 32(4), 863-873.

21 https://doi.org/10.1016/j.adolescence.2008.10.006

22 Yen, J.-Y., Yen, C.-F., Chen, C.-S., Tang, T.-C., \& Ko, C.-H. (2009). The Association between

23 Adult ADHD Symptoms and Internet Addiction among College Students: The Gender

24 Difference. CyberPsychology \& Behavior, 12(2), 187-191.

25 https://doi.org/10.1089/cpb.2008.0113 
Table 1: Characteristics of the participants

\begin{tabular}{|c|c|c|c|}
\hline & & Number & $\%$ \\
\hline \multirow[t]{2}{*}{ Gender } & Male & 158 & 31.23 \\
\hline & Female & 348 & 68.77 \\
\hline \multirow[t]{4}{*}{ Age } & $21-24$ & 48 & 9.41 \\
\hline & $25-29$ & 183 & 35.88 \\
\hline & $30-39$ & 227 & 44.51 \\
\hline & $>=40$ & 52 & 10.20 \\
\hline \multirow[t]{3}{*}{ Marital status } & Single & 236 & 46.18 \\
\hline & Married & 259 & 50.68 \\
\hline & Divorced & 16 & 3.13 \\
\hline \multirow[t]{4}{*}{ Number of children } & 0 & 286 & 56.19 \\
\hline & 1 & 67 & 13.16 \\
\hline & 2 & 64 & 12.57 \\
\hline & $>=3$ & 92 & 18.07 \\
\hline \multirow[t]{2}{*}{ Educational level } & Master & 342 & 67.72 \\
\hline & $\mathrm{PhD}$ & 163 & 32.28 \\
\hline \multirow[t]{5}{*}{ Academic year } & First & 136 & 26.93 \\
\hline & Second & 162 & 32.08 \\
\hline & Third & 103 & 20.40 \\
\hline & Fourth & 52 & 10.30 \\
\hline & Fifth & 52 & 10.30 \\
\hline \multirow[t]{2}{*}{ Being outside the country } & Yes & 173 & 33.86 \\
\hline & No & 338 & 66.14 \\
\hline
\end{tabular}


Table 3: Relation between smartphone addiction and Characteristics of the participants

\begin{tabular}{|c|c|c|c|c|c|c|}
\hline & & \multicolumn{2}{|c|}{$\begin{array}{l}\text { High smartphone use } \\
\text { group (261) }\end{array}$} & \multicolumn{2}{|c|}{$\begin{array}{l}\text { Low smartphone use } \\
\text { group }(251)\end{array}$} & \multirow[t]{2}{*}{$\begin{array}{l}P \\
\text { value }\end{array}$} \\
\hline & & Number & $\%$ & Number & $\%$ & \\
\hline \multirow[t]{2}{*}{ Gender } & Male & 88 & 33.8 & 70 & 28.5 & \multirow{2}{*}{0.191} \\
\hline & Female & 172 & 66.2 & 176 & 71.5 & \\
\hline \multirow[t]{4}{*}{ Age } & $21-24$ & 17 & 6.5 & 31 & 12.4 & \multirow{4}{*}{$0.026^{\prime}$} \\
\hline & $25-29$ & 105 & 40.2 & 78 & 31.3 & \\
\hline & $30-39$ & 117 & 44.8 & 110 & 44.2 & \\
\hline & $>=40$ & 22 & 8.4 & 30 & 12.0 & \\
\hline \multirow[t]{3}{*}{ Marital status } & Single & 115 & 44.1 & 121 & 48.4 & \multirow{3}{*}{0.268} \\
\hline & Married & 135 & 51.7 & 124 & 49.6 & \\
\hline & Divorced & 11 & 4.2 & 5 & 2.0 & \\
\hline \multirow[t]{4}{*}{ Number of children } & 0 & 147 & 56.3 & 139 & 56.0 & \multirow{6}{*}{0.867} \\
\hline & 1 & 37 & 14.2 & 30 & 12.1 & \\
\hline & 2 & 31 & 11.9 & 33 & 13.3 & \\
\hline & $>=3$ & 46 & 17.6 & 46 & 18.5 & \\
\hline \multirow[t]{2}{*}{ Educational level } & Master & 180 & 69.2 & 162 & 66.1 & \\
\hline & PhD & 80 & 30.8 & 83 & 33.9 & \\
\hline \multirow[t]{5}{*}{ Academic year } & First & 80 & 30.8 & 56 & 22.9 & \multirow{5}{*}{0.349} \\
\hline & Second & 80 & 30.8 & 82 & 33.5 & \\
\hline & Third & 48 & 18.5 & 55 & 22.4 & \\
\hline & Fourth & 27 & 10.4 & 25 & 10.2 & \\
\hline & Fifth & 25 & 9.6 & 27 & 11.0 & \\
\hline \multirow{2}{*}{$\begin{array}{l}\text { Being outside the } \\
\text { country }\end{array}$} & Yes & 94 & 36.2 & 79 & 31.5 & \multirow{2}{*}{0.264} \\
\hline & No & 166 & 63.8 & 172 & 68.5 & \\
\hline \multirow[t]{4}{*}{ Monthly income } & $5000 \mathrm{SR}$ & 104 & 40.3 & 92 & 39.3 & \multirow{4}{*}{0.952} \\
\hline & $\begin{array}{l}5000-10000 \\
\text { SR }\end{array}$ & 71 & 27.5 & 67 & 28.6 & \\
\hline & $\begin{array}{l}10000- \\
20000 \mathrm{SR}\end{array}$ & 69 & 26.7 & 60 & 25.6 & \\
\hline & $>20000 \mathrm{SR}$ & 14 & 5.4 & 15 & 6.4 & \\
\hline \multirow{2}{*}{$\begin{array}{l}\text { Monthly income for } \\
\text { father or mother or } \\
\text { both }\end{array}$} & $5000 \mathrm{SR}$ & 79 & 30.5 & 60 & 25.1 & \multirow[b]{2}{*}{0.425} \\
\hline & $\begin{array}{l}5000-10000 \\
\text { SR }\end{array}$ & 59 & 22.8 & 54 & 22.6 & \\
\hline
\end{tabular}


$10000-$

20000 SR

Table 4: Relation between smartphone addiction and Smoking, Depression, Insomnia, Physical Activity and ADHD symptoms.

\begin{tabular}{|c|c|c|c|c|c|c|}
\hline & & $\begin{array}{l}\text { Smartph } \\
\text { addiction }\end{array}$ & & $\begin{array}{l}\text { No sm } \\
\text { addiction }\end{array}$ & phone & $P$ value \\
\hline & & Number & $\%$ & Number & $\%$ & \\
\hline & Yes & 22 & 8.4 & 31 & 12.4 & \\
\hline & low independence & 7 & 2.7 & 20 & 8.0 & \\
\hline & $\begin{array}{l}\text { low to } \\
\text { mod independence }\end{array}$ & 6 & 2.3 & 4 & 1.6 & $0.039 *$ \\
\hline & $\begin{array}{l}\text { moderate } \\
\text { independence }\end{array}$ & 7 & 2.7 & 6 & 2.4 & \\
\hline & high independence & 2 & .8 & 1 & .4 & \\
\hline & No Smoking & 239 & 91.6 & 220 & 87.6 & \\
\hline & Moderate depression & 20 & 7.7 & 20 & 8.0 & \\
\hline Depression & $\begin{array}{l}\text { Moderately severe } \\
\text { depression }\end{array}$ & 42 & 16.1 & 11 & 4.4 & $0.013^{*}$ \\
\hline
\end{tabular}




\begin{tabular}{|c|c|c|c|c|c|c|}
\hline & Severe depression & 27 & 10.3 & 15 & 6.0 & \\
\hline & No Depression & 172 & 65.9 & 205 & 81.7 & \\
\hline \multirow[t]{3}{*}{ Insomnia } & insomnia & 151 & 65.7 & 99 & 44.4 & \multirow{3}{*}{$<0.001^{*}$} \\
\hline & & & & & & \\
\hline & no insomnia & 79 & 34.3 & 124 & 55.6 & \\
\hline \multirow{2}{*}{$\begin{array}{l}\text { ADHD } \\
\text { symptoms }\end{array}$} & have ADHD symptoms & 110 & 47.8 & 44 & 19.7 & \multirow{2}{*}{$<0.001^{*}$} \\
\hline & $\begin{array}{l}\text { have not ADHD } \\
\text { symptoms }\end{array}$ & 120 & 52.2 & 179 & 80.3 & \\
\hline
\end{tabular}

1

2

3

4

5

6

7

8

9

10

Table 5: Multivariate associations between Smoking, Depression, Insomnia, with ADHD symptoms with smartphone addiction

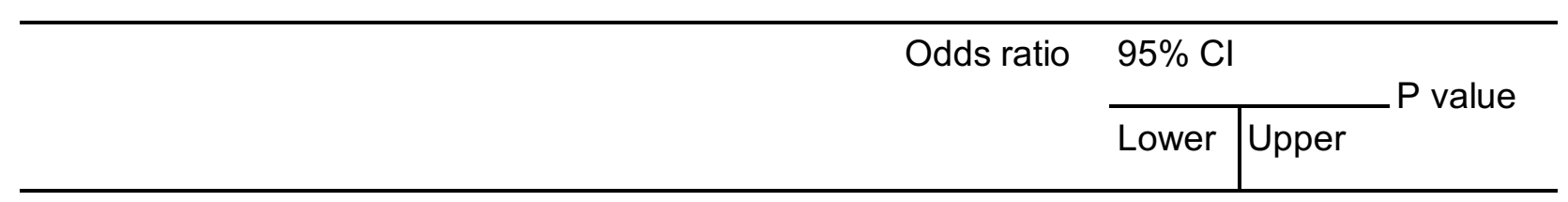




\begin{tabular}{|c|c|c|c|c|c|}
\hline \multirow[t]{4}{*}{ Depression } & $\begin{array}{l}\text { Clinically significant } \\
\text { depression }\end{array}$ & 1.261 & 0.562 & 2.829 & 0.574 \\
\hline & $\begin{array}{l}\text { Moderately severe } \\
\text { depression }\end{array}$ & 1.43 & 0.508 & 4.023 & 0.498 \\
\hline & Severe depression & 3.779 & 1.317 & 10.846 & $0.013^{*}$ \\
\hline & No Depression ${ }^{* *}$ & 1 & & & \\
\hline \multirow[t]{2}{*}{ Insomnia } & insomnia & 2.113 & 1.372 & 3.255 & $0.001^{*}$ \\
\hline & no insomnia & 1 & & & \\
\hline \multirow[t]{2}{*}{ ADHD symptoms } & have ADHD symptoms & 2.712 & 1.682 & 4.374 & $<0.001^{*}$ \\
\hline & $\begin{array}{l}\text { have not ADHD } \\
\text { symptoms }\end{array}$ & 1 & & & \\
\hline
\end{tabular}

* Significant $p$ value

${ }^{* *}$ used as reference 